\title{
Eradication of Helicobacter pylori restores the inhibitory effect of cholecystokinin on postprandial gastrin release in duodenal ulcer patients
}

\author{
J W Konturek, A Gillessen, S J Konturek, W Domschke
}

\begin{abstract}
Helicobacter pylori infection may be associated with duodenal ulcer (DU) and accompanied by enhanced gastrin release but the mechanism of this $H$ pylori related hypergastrinaemia in DU patients is unclear. Cholecystokinin (CCK) has been implicated in the feedback control of gastrin release and gastric acid secretion in healthy subjects. This study therefore investigated if CCK participates in the impairment of postprandial gastrin release and gastric secretion in six DU patients. Tests were undertaken with and without elimination of endogenous CCK by loxiglumide, a selective CCK-A receptors antagonist, before and after eradication of $\boldsymbol{H}$ pylori with triple therapy (omeprazole, amoxicyllin, bismuth). In $H$ pylori positive DU patients, the postprandial decline in pH (with median pH 3.5) was accompanied by a pronounced increment in plasma gastrin but the administration of loxiglumide did not affect significantly this postprandial rise in plasma gastrin and gastric $\mathbf{p H}$ profile. After eradication of $\boldsymbol{H}$ pylori, the plasma gastrin concentration was reduced while the median postprandial $\mathbf{p H}$ was significantly increased (median pH 4.3). The administration of loxiglumide resulted in significantly greater increase in postprandial plasma gastrin and greater decrease in $\mathrm{pH}$ (median $\mathrm{pH} 3 \cdot 1$ ) in these patients. This study shows that (a) infection with $H$ pylori is accompanied by an enhanced gastrin release and gastric acidity in DU patients, (b) the failure of loxiglumide to affect plasma gastrin or gastric acid secretion in $H$ pylori infected DU patients could be attributed, at least in part, to the failure of endogenous CCK to control gastrin release and gastric secretion by releasing somatostatin, and (c) the test with loxiglumide may be useful in the identification of patients with impaired feedback control of gastrin release and gastric secretion resulting from infection with $\boldsymbol{H}$ pylori.

(Gut 1995; 37: 482-487)
\end{abstract}

Keywords: Helicobacter pylori, gastrin, CCK, CCK receptors. Dr J W Konturek, Department of Medicine B, University of Münster, Albert-Schweitzer-Str 33, 48129 Munster, Germany.

Accepted for publication 24 February 1995
Duodenal ulcer (DU) patients, as a group, tend to secrete more acid than normal subjects both at rest and in response to secretory stimulation. ${ }^{1}$ As, after ingestion of a meal, the important stimulant of gastric acid secretion is an increased plasma gastrin, ${ }^{2-4}$ the DU patients have been reported to have higher plasma gastrin response to a meal and to exhibit an impaired inhibition of gastrin release at lower intragastric $\mathrm{pH}^{5}$ Other studies showed that endogenous cholecystokinin (CCK) may be implicated in the feedback control of gastrin release and gastric acid secretion ${ }^{6} 7$ because the administration of loxiglumide, a highly selective antagonist of CCKA receptors, ${ }^{6-8}$ greatly enhanced the plasma gastrin and gastric acid secretion in response to ordinary feeding, protein meal or gastrin releasing peptide. Moreover, DU patients were found to exhibit the defect in the inhibitory action of endogenous $\mathrm{CCK}^{9-12}$ on gastric release and gastric acid secretion suggesting an important role of CCK in the feedback control of gastric secretory functions.

The role of CCK as 'enterogastrone' in the control of gastric secretion by duodenal acid or fat has also been tested in dogs using highly selective CCK receptor antagonists such as L364,718. ${ }^{1314}$ These studies confirmed that CCK released by a peptone meal, especially when combined with fat ${ }^{13}$ or acid, ${ }^{14}$ exerts a potent inhibitory influence on gastric acid secretion and gastrin release through enhancing the release of endogenous somatostatin. Also in DU patients the defect in the inhibitory action of CCK on gastric secretion ${ }^{10-12}$ has been suggested to result from the failure of CCK to activate (through the CCK-A receptors) the $\mathrm{D}$ cells to release somatostatin because loxiglumide in these patients did not affect significantly the plasma somatostatin concentration. ${ }^{10}$

More recently it was found that chronic infection of $H$ pylori can be found in up to $90 \%$ of DU patients and is usually accompanied by non-specific antral gastritis. ${ }^{15-17}$ It has been suggested that chronic $H$ pylori infection may lead to DU disease because of an inappropriate gastrin release and subsequent enhancement in gastric acid secretion. In other reports reduction in postprandial gastrin responses after eradication of $H$ pylori in DU patients have been shown. ${ }^{18-20}$ Furthermore, studies on asymptomatic (without DU) subjects infected with $H$ pylori showed that these subjects have a significantly higher peptone meal induced plasma gastrin concentration and significantly attenuated inhibition of plasma gastrin at low 
intragastric $\mathrm{pH}$ compared with uninfected asymptomatic subjects. ${ }^{21}$ It was proposed that the impaired inhibition of gastrin release and gastric acid secretion seen previously in DU patients ${ }^{5}$ may be related to the infection of $H$ pylori in these patients.

This study was designed to assess the possible role of endogenous CCK in the impaired control of gastrin release in DU patients before and after eradication of H pylori.

\section{Methods}

\section{Subjects}

Studies were approved by the Research and Human Use Committee at the University Medical School, Krakow and written consent was obtained from each subject.

Studies included 10 male patients, their ages ranged from 22 to 28 years (mean age 24). All of them had active DU diagnosed by clinical history and actual gastroduodenal endoscopy. All of them had two or more episodes of symptomatic relapse within one year. None had symptoms of ulcer disease at the time of study. All drugs were withdrawn for three days before the examination.

\section{Study protocol}

Subjects were studied on three separate days before and after eradication of $H$ pylori. On one day, $H$ pylori status was tested using two endoscopic biopsy specimens obtained from the lesser curvature of the middle antrum. One specimen was assessed histologically and one by the rapid urease test for evidence of $H$ pylori infection. For histological assessment, the specimen was fixed in $10 \%$ buffer formalin, embedded in paraffin wax, and sectioned. Sections were stained with haematoxylin and eosin with Giemsa for detection of $H$ pylori. The second specimen was used for rapid urease CLO test (Delta West Pty, Bentley, Western Australia). Only $H$ pylori positive subjects were included in further studies.

\section{Gastric secretory studies with intragastric $p H$ monitoring}

On a second day, gastric acid secretion was studied for one hour under basal conditions and then for three hours after standard liquid $500 \mathrm{kcal}$ meal $(500 \mathrm{ml}$ Fresubin, Fresenius, Germany). This meal consisted of protein $(3.8 \%)$, aminoacids $(0.6 \%)$, carbohydrates $(14 \%)$, fat $(3.8 \%)$, minerals, vitamins, and water with osmolarity of about $300 \mathrm{mOsm} / \mathrm{l}$ and $\mathrm{pH}$ of about $6 \cdot 0$.

Throughout the examination period, the intragastric $\mathrm{pH}$ was monitored by means of an intraluminal system including the $\mathrm{pH}$ antimony electrode (Monocrystal model 9-0215, Synectics AB, Sweden) connected to the portable apparatus, which permitted the $\mathrm{pH}$ recording to be sampled every four seconds (Digitrapper MKII, 6200, Synectics AB, Sweden). The antimony electrode used an external reference on the thorax with contact jelly (Hellige 217, Fritz Hellige, Germany). At the beginning and at the end of each examination, the $\mathrm{pH}$ electrode was accurately calibrated at $21^{\circ} \mathrm{C}$ with $\mathrm{pH} 7.01$ and $\mathrm{pH} 1.07$ (buffers 5001 and 5002, Synectics AB, Sweden) and a temperature correction for intragastric reading $\left(37^{\circ} \mathrm{C}\right)$ was performed as described before. ${ }^{22}$ The $\mathrm{pH}$ electrode was passed through an anaesthetised nostril and was positioned in the gastric corpus under fluoroscopic control roughly $15 \mathrm{~cm}$ below the lower oesophageal sphincter. The $\mathrm{pH}$ recording started at about 0800 and lasted four hours and this included 60 minutes of basal period and 180 minutes after digestion of liquid meal.

Data from intragastric $\mathrm{pH}$ monitoring were transferred to an IBM compatible computer (80386-IBM) programmed with Gastrogram version 5.50 serial No E1024 (Gastrosoft, Irvine, TX, USA) for calculation of mean and median $\mathrm{pH}$ values for each three hour postprandial period. Data from all six subjects treated with placebo and loxiglumide were analysed with the use of program STATpHAC II/PHARM, version 216 D3 (Gastrosoft, Irvine, TX, USA). Gastric acidity was expressed as $\mathrm{pH}$ and values from each subject were transferred into 10 minute median values. The median and mean three hour intragastric pHs were pre-defined for comparison between study days using Wilcoxon's signed rank test. Box and whisker plots of median and mean intragastric $\mathrm{pH}$ in six patients were calculated for a three hour period after standard meal and compared in medians and means with a significance value of less than $0 \cdot 05$.

Each subject was tested twice before and twice after eradication of $H$ pylori using (a) standard liquid meal with oral administration of a placebo tablet 30 minutes before meal and (b) standard meal and oral administration of a loxiglumide tablet $(1200 \mathrm{mg})$ given 30 minutes before meal.

Eradication of $H$ pylori was achieved with triple therapy including amoxycillin, $500 \mathrm{mg}$ three times daily, for two weeks omeprazole (20 mg twice daily) for two weeks, and colloidal bismuth subcitrate, $120 \mathrm{mg}$ four times daily for four weeks. Endoscopy performed four weeks after the ending of treatment showed complete ulcer healing in all examined patients but the second test for eradication of $H$ pylori including ${ }^{13} \mathrm{C}$ urea breath test showed $H$ pylori eradication in only six of 10 treated patients. A second gastric secretory examination was performed five weeks after the end of treatment and was only carried out in $\mathrm{H}$ pylori negative patients.

\section{Radioimmunoassays}

Venous blood samples were obtained from a peripheral vein under basal conditions (twice) at 30 minute intervals before and after a standard meal (six times) before and after eradication of $H$ pylori in subjects receiving placebo or loxiglumide tablets. Plasma gastrin was determined using gastrin antiserum 4562 (kindly donated by Professor J E Rehfeld of 


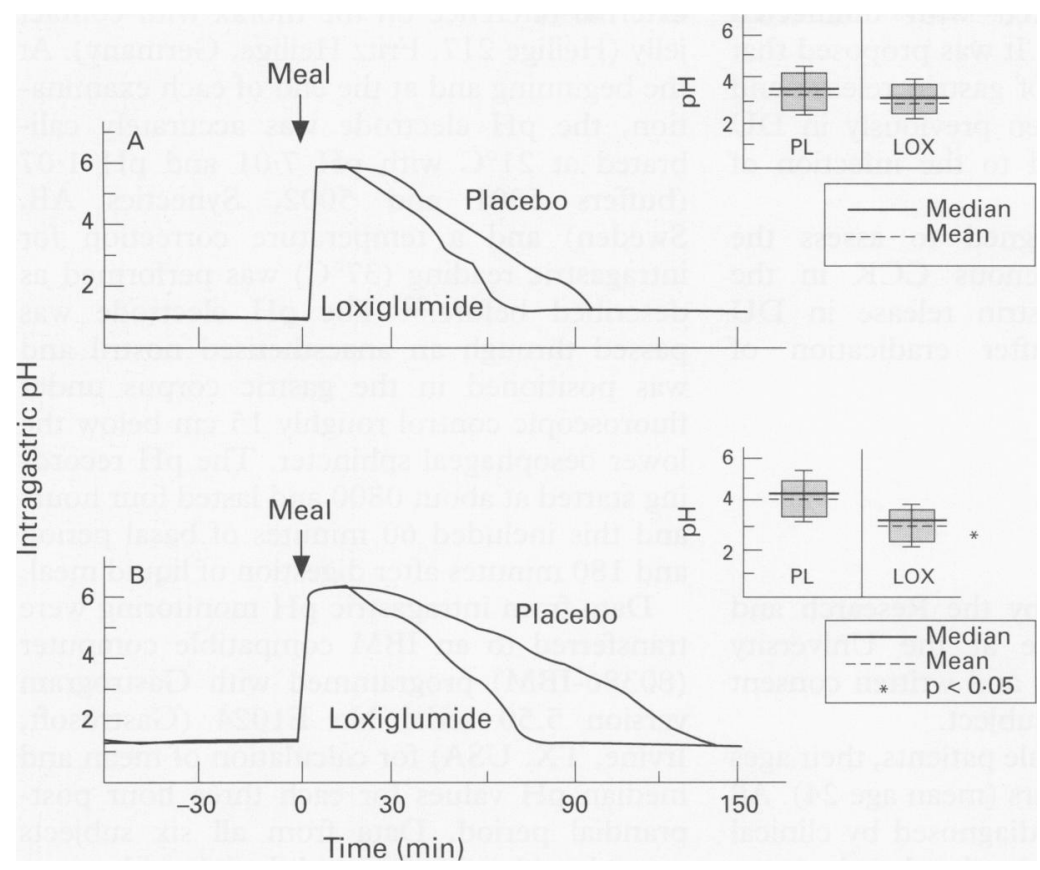

Figure 1: Median intragastric $p H$ in DU patients before $(A)$ and after $(B)$ eradication of $\mathrm{H}$ pylori before and after a standard meal in tests with administration of placebo or loxiglumide. Six tests on six patients. Box-whisker plots of three hour postprandial pH measurement period in tests with placebo (PL) or loxiglumide (LOX) treatment.

Copenhagen, Denmark) and used in a final dilution of 1:140 000. The antibody used recognises G17 and G34 equally. The sensitivity of the gastrin measurement in the present assay was $2.5 \mathrm{pmol} / \mathrm{ml}$ serum equivalent to human G-17 as described previously. ${ }^{23}$

Plasma CCK concentrations were determined by a radioimmunoassay using antiserum NY 11 (kindly provided by Professor N Yanaihara, Skizuoka, Japan), which recognises the sulphated residue of CCK-8 but has only negligible cross reactivity with sulphated G-17 $(<5 \%)$ and does not cross react with unrelated gastrointestinal peptides. Plasma samples were extracted with ethanol/acetic acid mixture, dried in a vacuum, and restituted with assay dilutent just before the assay. Synthetic sulphated human CCK-8 (gift of Professor $\mathrm{N}$ Yanaihara) was used as a standard and ${ }^{125}$ I-labelled with Bolton and Hunter reagent (Amersham, UK) as a tracer. ${ }^{11}$ The detection limit of the assay was $0.5 \mathrm{pmol} / \mathrm{ml}$ plasma CCK-8 standard. Intra-assay and interassay coefficients of variation were $8 \%$ and $12 \%$, respectively.

Plasma somatostatin was measured using a commercially available radioimmunoassay kit purchased from Milab, Malmo Immun-Labs $\mathrm{Ab}$, Malmo, Sweden as described. ${ }^{11}$ The antiserum used recognises only cyclic forms of somatostatin-14 and somatostatin-28 equally and did not cross react with any known gastrointestinal peptide. Plasma somatostatin was extracted with ethanol/acetic acid mixture, dried in a vacuum, and restituted as in the case of CCK. The detection limit was $0.5 \mathrm{pmol} / \mathrm{ml}$. Interassay and intra-assay variations were $8 \%$ and $12 \%$, respectively.

\section{Statistics}

The results of plasma hormones are expressed as means (SEM). Statistical significance was determined by both the Wilcoxon signed rank test and the paired $t$ test. Significance was accepted with a $\mathrm{p}$ value of less than 0.05 .

\section{Results}

Of $10 H$ pylori positive patients initially included in the study, only six had negative histological, rapid urease (CLO test), and ${ }^{13} \mathrm{C}$ urea breath tests four weeks after the end of triple therapy. The results presented in this report concern only the six subjects who showed negative $H$ pylor $i$ status and who completed the intragastric $\mathrm{pH}$ monitoring tests with placebo and loxiglumide before and after eradication of $H$ pylori.

Figure 1 shows the $\mathrm{pH}$ profile recorded during one hour of basal state and during three hours after ingestion of standard liquid meal. The $\mathrm{pH}$ value in $H$ pylori positive patients during the basal period was about $1 \cdot 1$ and was not significantly different between placebo and loxiglumide treated subjects. With the ingestion of a meal, the median $\mathrm{pH}$ immediately rose to about 6 and then slowly declined within about 90 minutes to the pre-meal value, the median $\mathrm{pH}$ for three hours of the postprandial period being about 3.5. In subjects treated with loxiglumide, the median $\mathrm{pH}$ also rose to $\mathrm{pH} 6.0$ and then declined to the pre-meal value within about 60 minutes, the median $\mathrm{pH}$ for the examined period (three hours) being about $3 \cdot 1$. The difference in the median postprandial $\mathrm{pH}$ between placebo and loxiglumide treated $H$ pylori positive DU patients was not statistically significant.

The $\mathrm{pH}$ profile in DU patients with negative $H$ pylori status, showed similar basal $\mathrm{pH}$ value (pH 1.3) and similar $\mathrm{pH}$ peak (about $\mathrm{pH} \mathrm{6)}$ after ingestion of standard meal. The return of intragastric $\mathrm{pH}$ after a meal to the pre-meal value occurred after about 120 minutes in placebo treated subjects and after about 60 minutes in loxiglumide treated subjects. The median $\mathrm{pH}$ for the examined period (three hours) was significantly lower in tests with loxiglumide $(\mathrm{pH} 3 \cdot 1)$ than in tests with placebo (pH 4.2).

Basal plasma gastrin, CCK, and somatostatin in placebo treated $H$ pylori positive DU patients averaged $27(3), 0.8(0.2)$, and 3.8 $(0 \cdot 3) \mathrm{pmol} / \mathrm{l}$. Ingestion of a standard liquid meal by those patients treated with placebo resulted in a significant increment (above basal) of plasma concentrations of gastrin (Fig 2), plasma CCK (Fig 3), and somatostatin (Fig 4) by about $88 \%, 150 \%$, and $68 \%$, respectively. In tests with loxiglumide basal plasma hormone concentrations were not significantly affected compared with placebo but the postprandial increments of plasma gastrin and somatostatin were similar to those seen in those patients after treatment with placebo. The increment of meal induced plasma CCK was almost twofold higher in tests with loxiglumide than with placebo.

After eradication of $H$ pylori in DU patients, the basal concentrations of plasma gastrin were significantly reduced, while plasma CCK and 


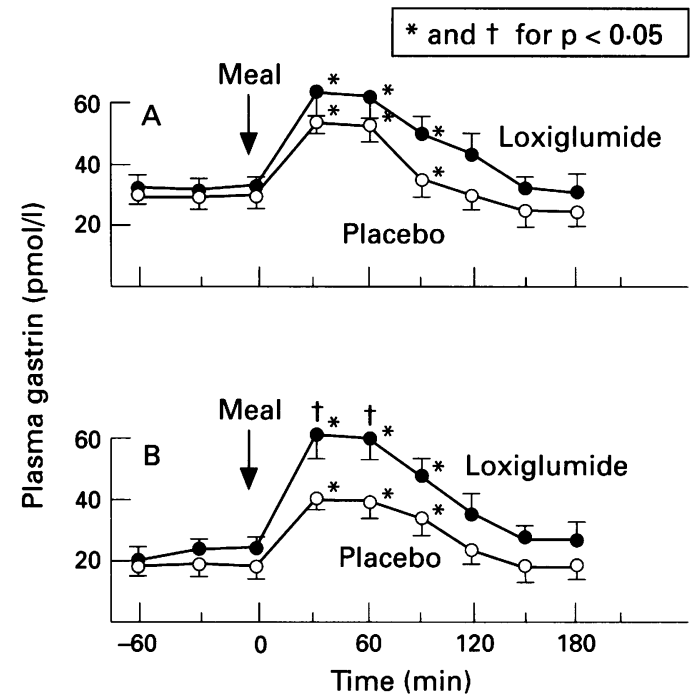

Figure 2: Plasma gastrin under basal conditions and after a standard meal in DU patients before $(A)$ and after $(B)$ eradication of $\mathrm{H}$ pylori in tests with placebo or loxiglumide. Mean of six tests on six patients. * Shows significant increase above the basal value; †shows significant change compared with the value obtained with placebo.

somatostatin values were similar to those in patients before the $H$ pylori eradication. The postprandial increment in plasma gastrin in placebo treated patients was similar to that seen in subjects before the eradication but in tests with loxiglumide, the increment in the postprandial plasma gastrin was about twice as high as in tests with placebo (Fig 2). The postprandial increment in plasma CCK concentrations in $H$ pylori negative DU patients treated with placebo were significantly lower than those in tests with loxiglumide. Thus, the administration of loxiglumide resulted in a significant rise in plasma CCK over that seen in placebo treated subjects both before and after the eradication of $H$ pylori (Fig 3 ).

Plasma somatostatin concentrations showed only a small increase over basal when a standard meal was given to placebo treated patients both with $H$ pylori positive and $H$ pylori negative status. On the other hand, in $H$ pylori negative DU patients, the increment in plasma somatostatin in tests with loxiglumide was significantly smaller than that in tests with placebo (Fig 4).

\section{Discussion}

This study confirms that eradication of $\mathrm{H}$ pylori in DU patients reduces plasma gastrin release $^{202425}$ and attenuates the postprandial gastric acid response in these patients. ${ }^{2025-28}$ The most important finding of this study is that the blockade of CCK-A receptors with loxiglumide in DU patients infected with $H$ pylori did not influence significantly the postprandial gastrin concentrations or gastric acid secretion but after eradication of $H$ pylori in the same patients, loxiglumide resulted in a pronounced increment in plasma gastrin concentrations similar to that seen previously in healthy subjects. ${ }^{67}$ These results could be interpreted that the $H$ pylori infection in DU is responsible for the increased basal plasma gastrin concentrations and increased gastric acid secretion and that these effects of $H$ pylori infection could be caused, at least in part, by the abolition of the gastric inhibitory effects of endogenous CCK.

Previous studies on healthy subjects showed that CCK exerts a potent inhibitory influence on gastrin release and gastric acid secretion in response to ordinary feeding or administration of gastrin releasing peptide. ${ }^{67}$ It has been proposed that CCK exerts a tonic inhibitory influence of gastric secretory functions and participates in the negative feedback control of gastrin release and gastric secretion. ${ }^{10}$ This suggestion was supported by the finding that the removal of the biological effects (by loxiglumide) of CCK either given exogenously or released endogenously by peptone meal or infusion of gastrin releasing peptide resulted in a pronounced increase in plasma gastrin and gastric acid secretion.

Our further studies with DU patients showed that blockade of CCK-A receptors with loxiglumide failed to influence the enhanced basal or postprandial plasma gastrin and gastric acid secretion in these patients suggesting an impaired inhibition of gastric functions by endogenous CCK possibly caused by the failure of this CCK to stimulate somatostatin release from the $\mathrm{D}$ cells. ${ }^{10-12}$ The implication of somatostatin in the 'enterogastrone-like' action of CCK originates from the studies on dogs ${ }^{10} 1314$ in which an addition to a peptone meal of fat or acid (which are known releasers of CCK) significantly inhibited gastrin release and gastric acid secretion. These inhibitory effects were completely eliminated by the blockade of CCK-A receptors with L-364,718, a specific antagonist of these receptors. As CCK is known to stimulate the release of somatostatin from isolated canine fundic $\mathrm{D}$ cells in vitro ${ }^{29}$ and the administration of $\mathrm{L}-367,718$ in vivo also reduced the postprandial release of somatostatin $^{1314}$ it was proposed that the major factor

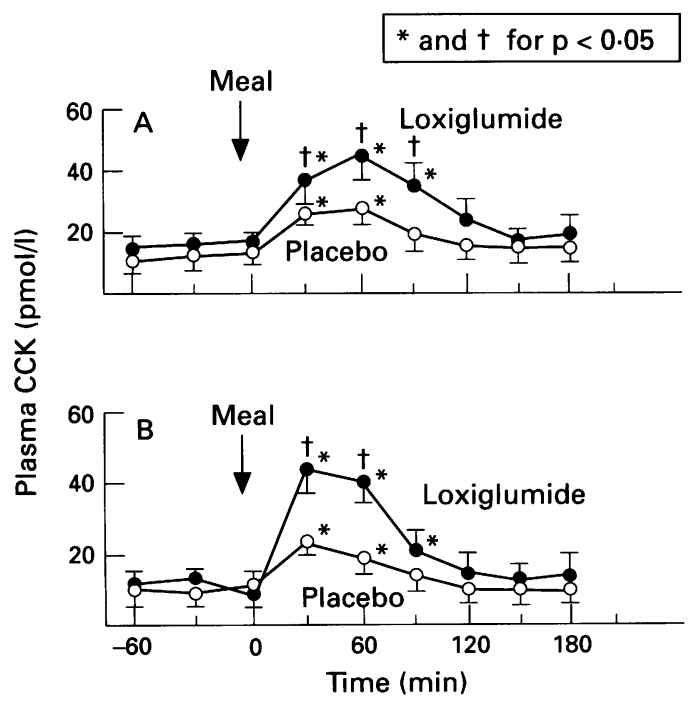

Figure 3: Plasma CCK concentrations under basal conditions and after a standard meal in DU patients before $(A)$ and after $(B)$ eradication of $\mathrm{H}$ pylori in tests with placebo or loxiglumide. Mean of six tests on six patients. ${ }^{\star}$ Shows significant increase above the basal value; $\dagger$ shows significant change compared with the value obtained with placebo. 
${ }^{*}$ and $\dagger$ for $p<0.05$

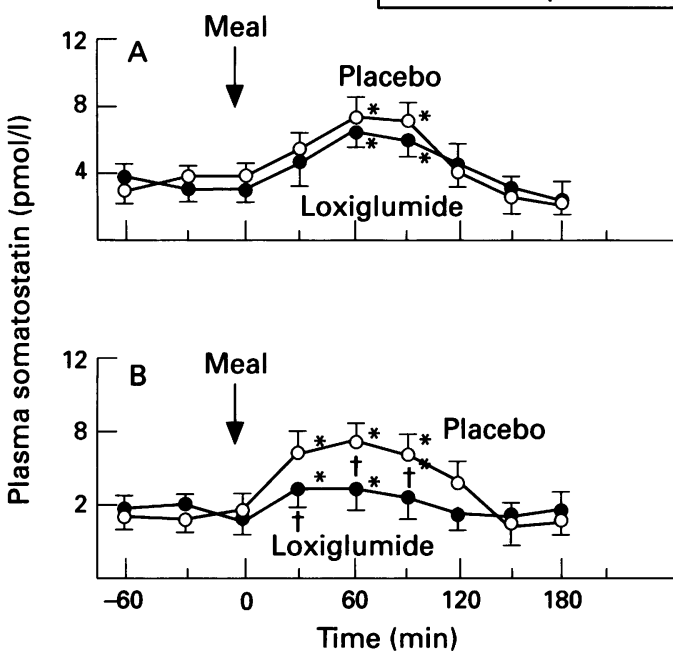

Figure 4: Plasma somatostatin concentrations under basal conditions and after a standard meal in DU patients before $(A)$ and after $(B)$ eradication of $\mathrm{H}$ pylori in tests with placebo or loxiglumide. Mean of six tests on six patients. ^Shows significant increase above the basal value; †shows significant change compared with the value obtained with placebo.

in the mechanism of gastric acid inhibition by CCK in dogs is probably somatostatin acting predominantly by a paracrine pathway on the $\mathrm{G}$ cells and oxyntic cells.

The somatostatin hypothesis in the control of gastric secretion in humans, particularly in DU patients, is attractive because the deficiency of somatostatin in DU patients has been suggested previously. ${ }^{30} 31$ The reports ${ }^{2627}$ that gastric $\mathrm{D}$ cells are suppressed in $H$ pylori positive duodenal ulcer disease offered an explanation for the deficient inhibitory pathway and support the somatostatin link in this disease. Our results show that after a standard meal in DU patients with or without $H$ pylori infection, there was a small but significant increment in plasma somatostatin, which may not be able by itself to inhibit gastrin release or gastric acid secretion but it may reflect the important changes in paracrine release of somatostatin by CCK just around the G cells or oxyntic cells. This could explain the apparent discrepancy between the pronounced increment in the postprandial plasma gastrin by loxiglumide in $H$ pylori negative DU patients and the comparatively small decrease in the concentrations of circulating plasma somatostatin. DU patients infected with $H$ pylori may exhibit the defective inhibitory action of endogenous CCK on paracrine release of somatostatin resulting in augmented basal plasma gastrin release and gastric acid secretion in response to a meal in these patients. After eradication of $H$ pylori, loxiglumide could suppress the release of somatostatin possibly by antagonising CCK-A receptors localised to these cells. The antagonism of CCK-A receptors and the fall in somatostatin output will remove the $G$ cells from the paracrine inhibitory influence of somatostatin with subsequent excessive postprandial release of gastrin and greatly increased gastric acidity. This is in keeping with our data that after the eradication of
$H$ pylori, a significant decrease in basal plasma gastrin and gastric acid responses to the meal was seen but the blockade of CCK-A receptors with loxiglumide resulted in a greatly increased postprandial gastrin release and enhanced gastric acid secretion, similar to those seen in healthy subjects. ${ }^{67}$ As no significant differences in plasma CCK and somatostatin values were seen before and after eradication of $H$ pylori, it is probable that in addition to the proposed CCK-somatostatin-gastrin link there are other factors, such as cytokines (for example, interleukin 1) that may impair the normal physiological feedback loop for gastrin regulation in chronic inflammation resulting from infection by $H$ pylori. Indeed, animals studies $^{32}$ showed that interleukin 1 given intravenously increased plasma gastrin concentration while inhibiting gastric acid secretion and these effects were mediated by the prostaglandin pathway. Further studies are needed to elucidate the relative contribution of various factors in the control of gastrin release and gastric secretion in the $H$ pylori infected patients.

It is of interest that loxiglumide resulted in a considerable increase in postprandial plasma CCK concentration both in $H$ pylori positive and $H$ pylori negative DU patients. This actually confirms previous findings ${ }^{6}$ regarding higher postprandial concentrations of circulating CCK in loxiglumide treated patients compared with placebo treated subjects. Higher plasma CCK concentrations in tests with loxiglumide were reported previously in healthy subjects $^{61112}$ and, according to this study, this is also true for DU patients after eradication of $H$ pylori.

Our results show that the infection of $H$ pylori not only enhanced gastrin release but also increased postprandial gastric acid secretion as reported by some investigators 152425 but this is a controversial issue because other reports showed that $H$ pylori infection is accompanied by hypergastrinaemia but not by hyperchlohydria ${ }^{28} 3334$ or increased integrated 24 hour intragastric acidity. ${ }^{35}$

1 Baron JH. The clinical use of gastric function tests. Scand $\mathcal{f}$ Gastroenterol 1970; 6 (suppl): 9-17.

2 Feldman M, Walsh JA, Wong HG, Richardson CT. Role of gastrin heptadecapeptide in the acid secretory response to
amino acids in man. Gastroenterology 1978; 61: 303-13.

3 Eysselein VE, Kovacs TOG, Kleibenker JH, Maxwell V, Reedy T, Walsh JH. Regulation of gastric acid secretion by gastrin in duodenal ulcer patients and healthy subjects. by gastrin in duodenal ulcer patients

4 Walsh JH. Gastrin. In: Walsh JH, Dockray GJ, eds. Gut Walsh JH. Gastrin. In: Walsh JH, Dockray GJ,
peptides. New York: Raven Press, 1974: 75-122.

5 Walsh JH, Richardson CT, Fordtran JS. pH dependence of acid secretion and gastrin release in normal and ulcer patients. F Clin Invest 1975; 55: 462-8.

6 Beglinger C, Hildebrand P, Meier $R$, Bauerfeind P, Hasslocher $\mathrm{H}$, Urscheler $\mathrm{N}$, et al. A physiological role for cholecystokinin as a regulator of gastrin secretion. Gastroenterology 1992; 103: 490-5.

7 Konturek JW, Maczka J, Garlicki A, Gabryelewicz A, Rovati L, Domschke W, et al. Cholecystokinin (CCK) in the control of gastric secretion in man. Gut 1993; 34: 321-8.

8 Setnikar I, Christe R, Makovec F, Rovati LC, Warrington RT. Pharmacokinetics of loxiglumide after single intraRT. Pharmacokinetics of loxiglumide after single intra-
venous or oral doses in man. Artzneimittelforshung 1988; 39: $716-20$.

9 Gross RA, Isenberg II, Hogen D, Samloff IM. Effect of fat on meal-stimulated duodenal acid load, duodenal pepsin on meal-stimulated duodenal acid load, duodenal pepsin load, and serum gastrin in duodenal ulcer

10 Konturek JW, Konturek SJ, Domschke W. Role of cholecystokinin in the control of gastric acid secretion and gastrin release in dogs and healthy and duodenal ulcer subjects. Scand f Gastroenterol 1993; 28: 657-60. 
11 Konturek JW, Thor P, Maczka M, Domschke W, Konturek SJ. Role of CCK in the control gastric secretory pattern in response to fatty meal in normal subjects and duodenal
ulcer patients. Scand $\mathcal{f}$ Gastroenterol 1994; 29: 583-90.

12 Konturek JW, Maczka M, Stoll R, Konturek SJ, Domschke W. Cholecystokinin (CCK) in the inhibition of gastric acid secretion and gastrin release in response to meals of low and high $\mathrm{pH}$ in healthy subjects and duodenal ulcer patients. Gastroenterology 1994; 106: A1 10.

13 Lloyd KC, Maxwell V, Kovass TO, Walsh JH. Cholecystokinin receptor antagonist MK-329 blocks intestinal fat-induced inhibition of meal-stimulated gastric acid secretion. Gastroenterology 1992; 102: 131-8.

14 Konturek SJ, Bilski J, Tasler J, Cieszkowski M. Role of cholecystokinin in the inhibition of gastric acid secretion in dogs. $\mathcal{F}$ Physiol 1992; 451: 477-98.

15 Levi S, Beardshall K, Desa LA, Calam J. Campylobacter pylori, gastrin, acid secretion, and duodenal ulcer. Lancet pylori, gastrin

16 Levi S, Haddad G, Ghosh P, Beardshall K, Playford R, Calam J. Campylobacter pylori and duodenal ulcer: the gastrin link. Lancet 1989; i: 1167-8.

17 Chamberlain CE, Peura DA. Campylobacter (Helicobacter) pylori - is peptic disease a bacterial infection? Arch Intern Med 1990; 150: 951-5.

18 McColl KEL, Fullarton GM, El Nujumi AM, MacDonald AM. Lowered gastrin and gastric acidity after eradication of Campylobacter pylori in duodenal ulcer. Lancet 1989; ii: 499-500.

19 Graham DY, Opekun A, Lew GM, Evans DJ, Klein PD, Evans DG, et al. Ablation of exaggerated meal-stimulated gastrin release in duodenal ulcer patients after clearance of Helicobacter (Campylobacter) pylori infection. Am $\mathcal{F}$ Gastroenterol 1990; 85: 394-8.

20 Konturek PCh, Konturek SJ. Role of Helicobacter pylori infection in gastro-duodenal secretion and pathogenesis of peptic ulcer and gastritis. $\mathcal{F}$ Physiol Pharmacol 1994; 45: 333-50.

21 Tarnasky PR, Kovacs TOG, Sytnik B, Walsh JH. Asymptomatic $\mathrm{H}$ pylori infection impairs $\mathrm{pH}$ inhibition of gastrin and acid secretion during second hour of peptone meal stimulation. Dig Dis Sci 1993; 38: 1681-7.

22 Savarino V. Continuous intragastric pH monitoring, a real progress in the assessment of antisecretory drugs. Ital $\mathcal{f}$

Gastroenterol 1990; 22 (suppl 2): 10-23.
23 Konturek SJ, Swierczek J, Kwiecien N, Obtulowicz W,
Dobrzanska M, Kopp B, et al. Gastric secretory and plasma hormonal responses to sham-feeding of varying duration in patients with duodenal ulcer. Gut 1981; 22: 1003-10.

24 Mullin GE, Kallo AN. Does Helicobacter pylori infection affect gastric acid secretion. Gastroenterology 1990; 98: A92.

25 Moss SF, Calam J. Acid secretion and sensitivity to gastrin in patient with duodenal ulcer: effect of eradication of Helicobacter pylori. Gut 1993; 34: 888-92.

26 McHenry I, Vuyyuruu L, Schubert ML. Helicobacter pylori and duodenal ulcer disease: the somatostatin link? Gastroenterology 1993; 104: 1573-5.

27 Kaneko H, Nakada K, Mitsuma T, Uchida K, Furusawa A, Maeda $\mathrm{Y}$. $\mathrm{H}$ pylori infection induces a decrease in immunoreactive somatostatin concentrations in human immunoreactive somatostatin concentrati

28 Brady ECI, Hadfied TL, Hyatt JR, Utts SJ. Acid secretion and serum gastrin levels in individuals with Campylobacter pylori. Gastroenterology 1988; 94: 923-7. 29 Soll AH, Amirian DA, Park J, Elashoff JD, Yamada T. Cholecystokinin potently releases somatostatin from canine fundic mucosal cells in short-term culture. $\mathrm{Am} \mathcal{f}$ Physiol 1985; 248: G569-73.

30 Chayvialle JAP, Descos F, Bernard C, Martin A, Barbe C, Partensky C. Somatostatin in mucosa of stomach and duodenum in gastroduodenal disease. Gastroenterology 1978; 75: 13-9.

31 Harty RF, Malco DG, McGuigan JE. Antral release of gastrin and somatostatin in duodenal ulcer and control gastrin and somatostatin in d

32 Seperas E, Comiinelli F, Tache Y. Potent inhibition of gastric acid secretion by intravenous interleukin-1 beta and -alpha in rats. Peptides 1992; 13: 221-6.

33 Katelaris PH, Seow F, Lin BPC, Napoli J, Ngu MC, Jones DB. Effect of age, Helicobacter pylori infection, and gastritis with atrophy on serum gastrin and gastric acid secretion in healthy men. Gut 1993; 34: 1032-7.

34 Haruma K, Kawaguchi H, Yoshihara M, Okamoto S, Sumii $K$, Kishimoto S, et al. Relationship between Helicobacter pylori infection and gastric acid secretion in young healthy pylori infection and gastric acid secretion in you

35 Vagner S, Gladziwa U, Haruma K, Varrentrapp M, Gabel E. Effect of Helicobacter pylori infection on $24 \mathrm{~h}$ intragastric acidity in patients with gastritis and duodenal ulcer. Gut 1992; 33: 1024-8. 